\title{
Suppression of interferometric crosstalk and ASE noise using a polarization multiplexing technique and an SOA
}

\author{
Zheng, Xueyan; Liu, Fenghai; Wolfson, David; Kloch, Allan
}

Published in:

I E E E Photonics Technology Letters

Link to article, DOI:

$10.1109 / 68.868018$

Publication date:

2000

Document Version

Publisher's PDF, also known as Version of record

Link back to DTU Orbit

Citation (APA):

Zheng, X., Liu, F., Wolfson, D., \& Kloch, A. (2000). Suppression of interferometric crosstalk and ASE noise using a polarization multiplexing technique and an SOA. I E E E Photonics Technology Letters, 12(8), 1091-1093. https://doi.org/10.1109/68.868018

\section{General rights}

Copyright and moral rights for the publications made accessible in the public portal are retained by the authors and/or other copyright owners and it is a condition of accessing publications that users recognise and abide by the legal requirements associated with these rights.

- Users may download and print one copy of any publication from the public portal for the purpose of private study or research.

- You may not further distribute the material or use it for any profit-making activity or commercial gain

- You may freely distribute the URL identifying the publication in the public portal 


\title{
Suppression of Interferometric Crosstalk and ASE Noise Using a Polarization Multiplexing Technique and an SOA
}

\author{
Xueyan Zheng, Fenghai Liu, David Wolfson, and Allan Kloch
}

\begin{abstract}
Noise suppression at $10 \mathrm{Gbit} / \mathrm{s}$ and $20 \mathrm{Gbit} / \mathrm{s}$ is demonstrated using a gain saturated semiconductor optical amplifier (SOA) and a polarization multiplexing technique, where no impairments like waveform distortion and extinction ratio degradation caused by the gain saturation of the SOA appear. Moreover, the method is bit rate transparent and the input power dynamic range is very large. Furthermore, the SOA can provide a high gain.
\end{abstract}

Index Terms-Interferometric crosstalk, noise suppression, polarization multiplexing, semiconductor optical amplifier.

\section{INTRODUCTION}

W AVELENGTH-DIVISION-MULTIPLEXING (WDM) networks have been installed on a global scale to satisfy the ever-increasing demand for communication capacity. In WDM networks, amplified spontaneous emission (ASE) from optical amplifiers and crosstalk at the signal wavelength (interferometric crosstalk) are serious problems [1]. So, it is very important to find effective techniques to suppress the impact of ASE noise and interferometric crosstalk. Several schemes have been demonstrated for noise suppression, including Mach-Zehnder interferometers [2], a wavelength converter based on cross gain modulation in a laser diode [3] and a gain saturated laser diode amplifier [4]. However, the Mach-Zehnder interferometer structure is complicated and the input power dynamic range is small. The method used in [3] inherently performs wavelength conversion and the conversion speed is limited by the recovery time of the carrier in the optical amplifier, moreover, there is a large undesired chirp is added to the signal. The method in [4] does not need wavelength conversion, but it suffers from extinction ratio (ER) degradation, waveform distortion at high input powers and it does not work at high bit rates because of the limited relaxation time.

In this paper, it is shown that signal fluctuations caused by interferometric crosstalk or ASE can be suppressed greatly at 10 or $20 \mathrm{Gbit} / \mathrm{s}$ using a gain saturated semiconductor optical amplifier(SOA) and a polarization multiplexing technique. Using polarization multiplexing of optical signals modulated by data and the complementary, the SOA experiences a constant input power instead of a transient power from the bit pattern and consequently impairments like waveform distortion and extinction ratio degradation from the SOA are eliminated. Moreover, the method is bit

Manuscript received January 1, 2000; revised April 12, 2000.

The authors are with the Research Center COM, Technical University of Denmark, Lyngby DK-2800, Denmark (e-mail: zx@com.dtu.dk).

Publisher Item Identifier S 1041-1135(00)06287-X. rate transparent and the input power dynamic range is very large In addition, the SOA can also provide high gain.

\section{PRINCIPLE OF THE MethoD}

When an SOA is gain saturated, the signal fluctuation caused by interferometric crosstalk or ASE noise can be reduced [3]. However, the ER of the output signal is reduced and the waveform is also distorted at high input power level due to the gain saturation. In order to avoid the above shortcomings, we multiplex the two optical signals with orthogonal polarization states which are modulated with data and the complementary respectively using a polarization beam combiner (PBC), hereby, obtain the multiplexed signals with a constant power as described in [5]. Since the SOA only experiences the constant optical power of the combined signals, no waveform distortions and ER degradation will be generated by the SOA. A polarization beam splitter (PBS) is used to demultiplex the signal. Fig. 1 shows the waveforms of the signals before the $\mathrm{PBC}$, before and after the SOA and after the PBS when the input power into the SOA is -2 $\mathrm{dBm}$, which is much higher than the $3-\mathrm{dB}$ gain saturated power. It can be seen from Fig. 1 that no ER degradation and waveform distortion is induced. Furthermore, the method is pattern independent and no chirp is added to the signal due to the constant input power to the SOA.

\section{EXPERIMENTAL SETUP}

Fig. 2 shows the experimental setup. Light from a DFB laser is divided into two parts after being amplified by an EDFA. Each part is modulated by data ( $2^{31-1}$ PRBS $)$ or the complementary in an external modulator, and then set to one of two orthogonal polarization states. The two parts are combined in the PBC. A variable fiber delay line and a variable optical attenuator (Att1) are used before the PBC, in order to obtain a constant power of the combined signal without bit transition patterns. Two kinds of noise are generated to add fluctuation to the signal before launched into the SOA, one is interferometric crosstalk, the other is ASE noise. The interferometric crosstalk is added to the combined signal by adding a fraction of the original signal delayed by $500-\mathrm{m}$ fiber. Att 2 before the $3-\mathrm{dB}$ coupler is used to control the input power to the SOA and Att3 is used to control the relative crosstalk power. ASE noise is generated by an EDFA. The signal is transmitted through in-line EDFA2, and then an optical filter with 1.3-nm bandwidth. Att4 before EDFA2 is used to control the input power. Thus, the optical signal-to-noise ratio at the input of the SOA can be controlled. 
DATA
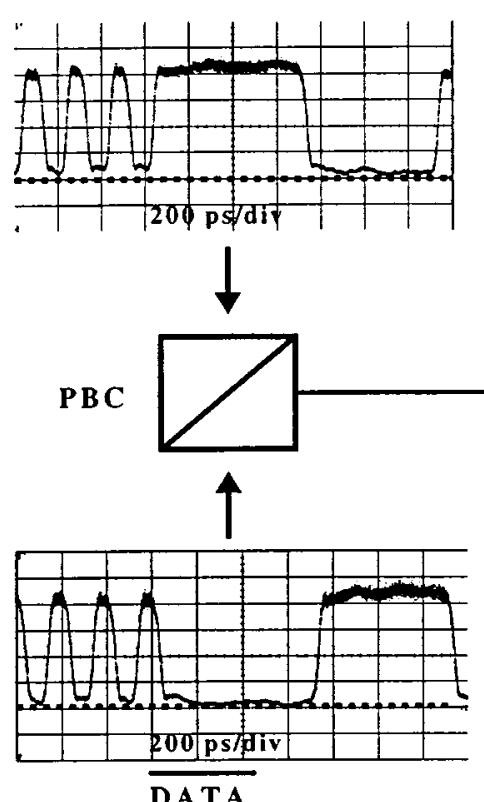
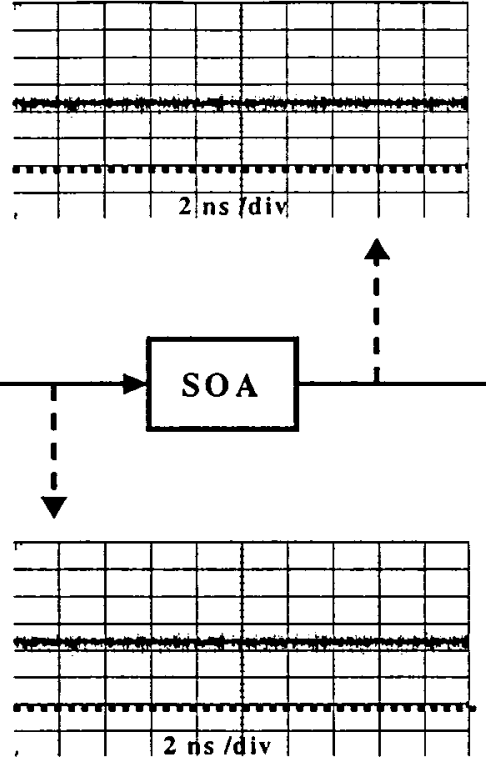
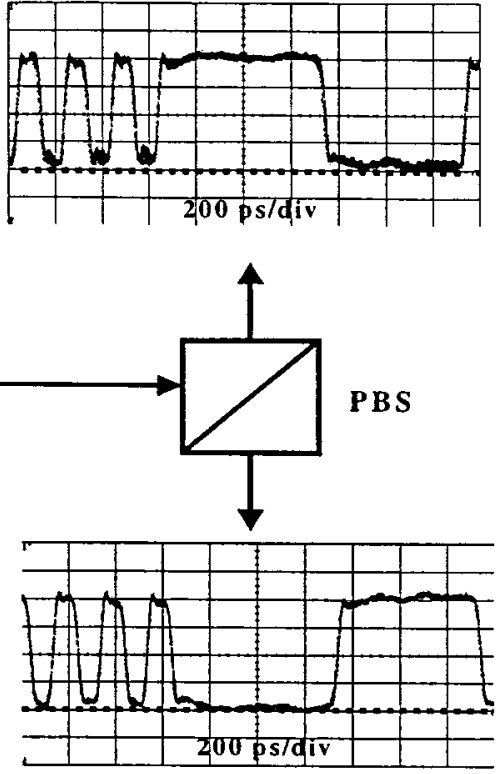

Fig. 1. Waveforms of the signal before polarization multiplexing, before and after the SOA and after the PBS. The input power into the SOA is $-2 \mathrm{dBm}$. PBC: Polarization beam combiner. PBS: Polarization beam splitter. SOA: Semiconductor optical amplifier.

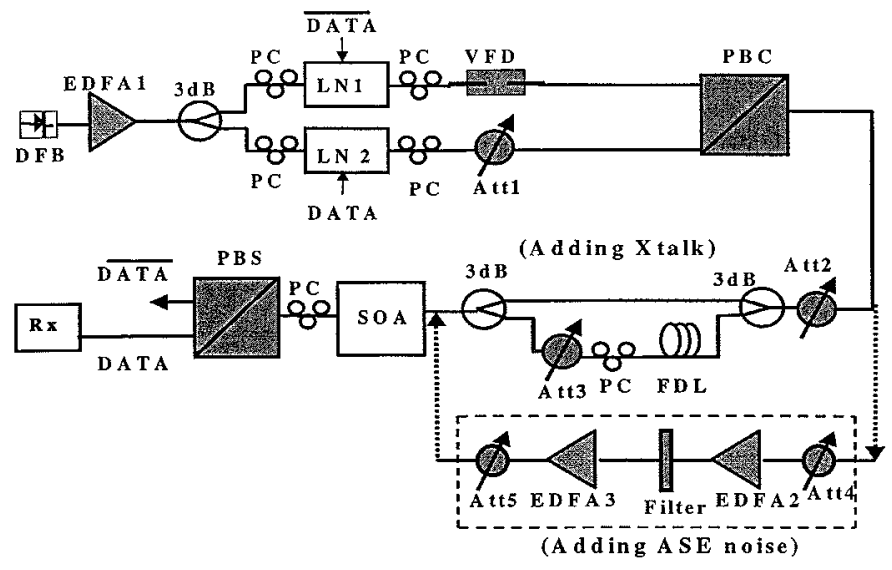

Fig. 2. Experimental setup. 3dB: 3-dB coupler. PC: Polarization controller. LN: Lithium Niobate modulator. VFD: Variable fiber delay line. PBC: Polarization beam combiner. Att: Variable optical attenuator. FDL: Fiber delay line. SOA: Semiconductor optical amplifier. PBS: Polarization beam splitter. Rx: Optical receiver.

The Att5 after EDFA3 is used to control the power into the SOA. The 3-dB saturation input power of the $\mathrm{SOA}$ is $-10 \mathrm{dBm}$, the gain peak of the SOA is at $1550 \mathrm{~nm}$ and the gain polarization-dependence of the SOA is $0.5 \mathrm{~dB}$. The two orthogonal polarized signals are separated by the PBS, both of them have the same performance and one of them is detected in a PIN receiver.When the crosstalk is added to the signal, the amplitude fluctuations caused by the beat noise between the signal and the crosstalk are suppressed significantly by the saturated SOA. Fig. 3(a) and (b) shows eye-diagrams of the $10 \mathrm{~Gb} / \mathrm{s}$ signal with $-13.8 \mathrm{~dB}$ crosstalk before and after the SOA. Seen from Fig. 3, a clear eye is restored after the SOA. Fig. 4.shows the penalties versus relative crosstalk power with and without the SOA at different input power levels. It can be seen from Fig. 4 that a $6 \mathrm{~dB}$ more crosstalk power can be tolerated using the SOA at a penalty of

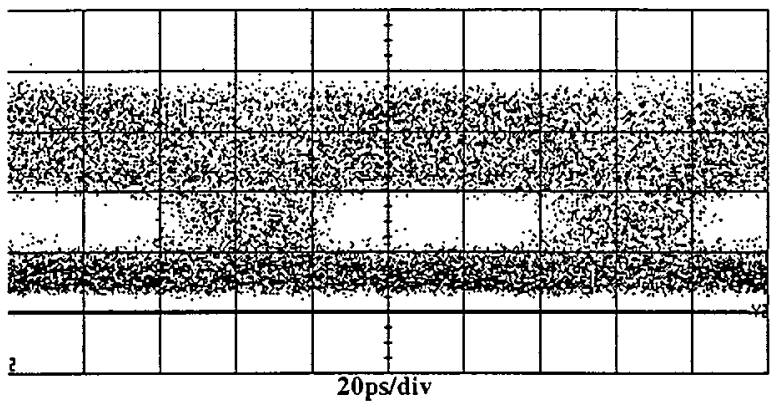

(a)

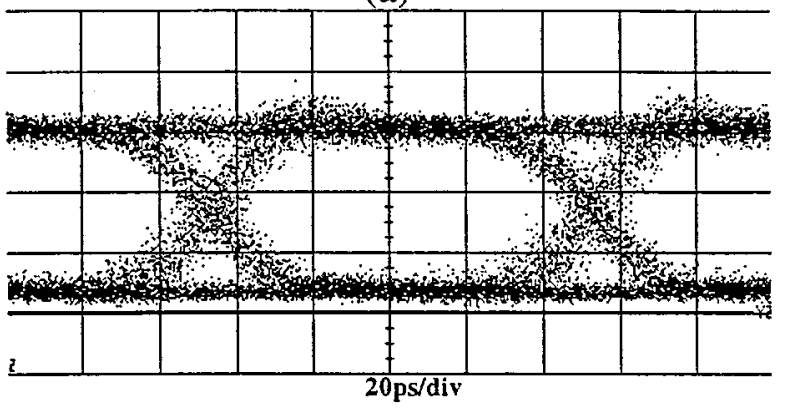

(b)

Fig. 3. Eye-diagrams of the signal with $-13.8 \mathrm{~dB}$ crosstalk before (a) and after (b) the SOA at $10 \mathrm{~Gb} / \mathrm{s}$.

$1 \mathrm{~dB}\left(\mathrm{BER}=10^{-9}\right)$ when the input power to the SOA is -6 $\mathrm{dBm}$. Because the ER degradation and waveform distortion are avoided, the input power dynamic range is very large. Seen from Fig. 4, when the input power changes from -10 to $4 \mathrm{dBm}, 4-6$ $\mathrm{dB}$ more crosstalk power can be tolerated by using the SOA at a penalty of $1 \mathrm{~dB}\left(\mathrm{BER}=10^{-9}\right)$. Since the saturated output power of the SOA is $+7 \mathrm{dBm}$, the SOA can also provide high gain. When the input power to the SOA is $-10 \mathrm{dBm}$, the gain is $+17 \mathrm{~dB}$, meanwhile, $4 \mathrm{~dB}$ more crosstalk can be tolerated. 


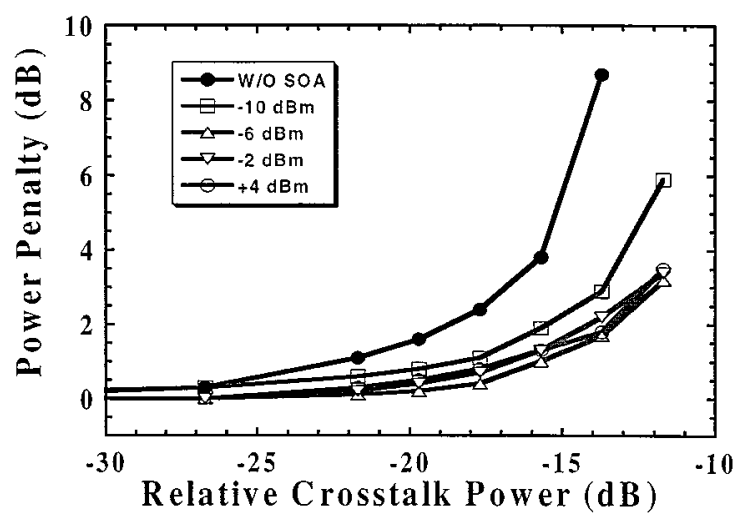

Fig. 4. Penalty as a function of relative crosstalk power for different input power level.

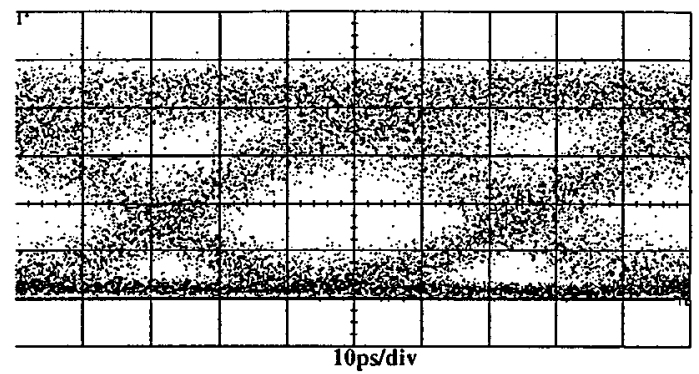

(a)

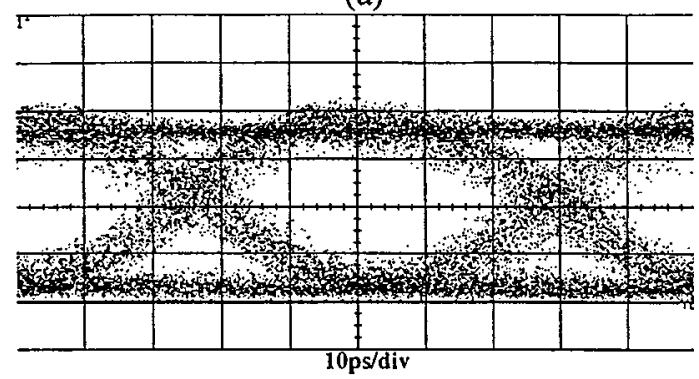

(b)

Fig. 5. Eye-diagrams of the signal with $-17.8 \mathrm{~dB}$ crosstalk before (a) and after (b) the SOA at $20 \mathrm{~Gb} / \mathrm{s}$.

\section{RESULTS AND DISCUSSIONS}

In general, this method can reduce any amplitude fluctuation with the frequency to which the SOA can respond, on the other hand, the electronical filter in the receiver will filter the noise with high frequency. Moreover, the waveform distortion and ER degradation are avoided, so, we can say that this method is bit rate transparent. The length of the SOA used in the experiment is $1.2 \mathrm{~mm}$, and the $3-\mathrm{dB}$ modulation bandwidth is larger than $30 \mathrm{GHz}$. So, effective noise suppression can be realized at very high bit rate using this method. Fig. 5(a) and (b) shows the eyediagrams at $20 \mathrm{~Gb} / \mathrm{s}$ before and after the SOA when the relative

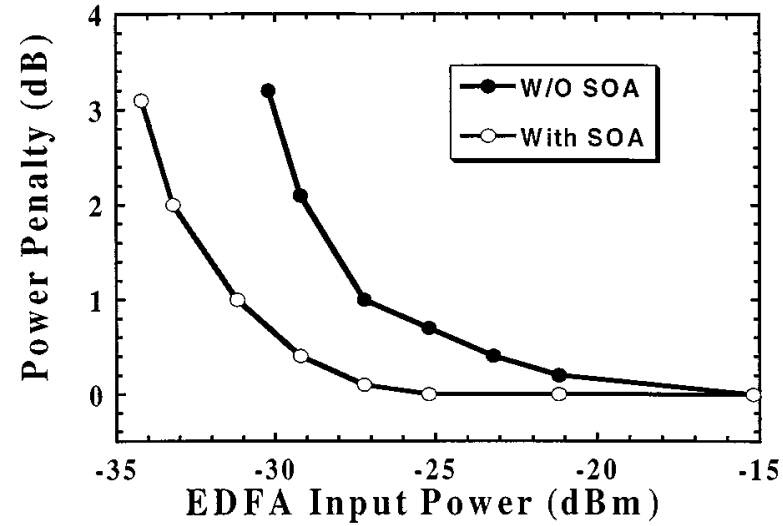

Fig. 6. Penalty as a function of the EDFA input power with and without the SOA at $10 \mathrm{Gbit} / \mathrm{s}$. The input power to the SOA is $-3 \mathrm{dBm}$.

crosstalk power is $-17.8 \mathrm{~dB}$; also here a clear eye can be found after the SOA. Due to lack of a $20 \mathrm{~Gb} / \mathrm{s}$ receiver, no BER curves are measured in this case.

ASE noise is also suppressed effectively using the same method. Fig. 6 shows the receiver penalty at $10 \mathrm{~Gb} / \mathrm{s}$ with and without the SOA as a function of the in-line EDFA input power. The input power to the SOA is $-3 \mathrm{dBm}$. As seen, the noise is suppressed and $4 \mathrm{~dB}$ lower input power to the EDFA is allowed at a penalty of $1 \mathrm{~dB}\left(\mathrm{BER}=10^{-9}\right)$.

\section{CONCLUSION}

We have successfully demonstrated that the impact of interferometric crosstalk and ASE noise can be suppressed using a saturated SOA and a polarization multiplexing technique. The method gives no waveform distortion or extinction ratio degradation. Besides the method is bit rate transparent and the input power dynamic range is very large, the SOA can also provide a high gain.

\section{REFERENCES}

[1] P. J. Legg, M. Tur, and I. Andonovic, "Solution paths to limit interferometric noise induced performance degradation in ASK/direct detection lightwave networks," J. Lightwave Technol., vol. 14, pp. 1943-1954, Sept. 1996.

[2] D. Wolfson, P. B. Hansen, T. Fjelde, A. Kloch, C. Janz, A. Coquelin, I. Guillemot, F. Gaborit, F. Poingt, and M. Renaud, " 40 Gbit/s all-optical $2 \mathrm{R}$ regeneration in an SOA-based all-active Mach-Zehnder interferometer," in Proc. OECC'99, Beijing, China, 1999, pp. 456-457.

[3] K. Inoue, "Noise transfer characteristic in LD wavelength conversion," J. Lightwave Technol., vol. 14, pp. 2763-2770, Dec. 1996.

[4] - "Suppression of signal fluctuation induced by crosstalk light in a gain saturated laser diode amplifier," IEEE Photon. Technol. Lett., vol. 8, pp. 458-460, Aug. 1996

[5] S. Banerjee, A. K. Srivastava, B. R. Eichenbaum, C. Wolf, Y. Sun, J. W. Sulhoff, and A. R. Chraplyvy, "Polarization multiplexing technique to mitigate WDM cross-talk in SOAs," in Proc. ECOC'99, vol. PD, 1999, pp. 62-63. 